\title{
The Large Age-Groups and Migration
}

\author{
By PEKKA MYRSKYLÄ \\ Central Statistical Office of Finland
}

In Finland the working-age population has continually increased. In the 1950 s the increase was double that of the 1940 s or 300000 persons. In the 1960 s the working-age population increased by further 100000 persons. The rapid growth in the working-age population took place during a record-breaking period of rapid transition in the industrial structure. The number of jobs in agriculture dropped at a rapid rate. Were it not for emigration the increase in the working-age population in the 1960 s would have brought about a labor force supply necessitating about $40 \%$ more jobs than were available in e.g. 1960 s.

The increase in the labor force supply was caused by the large age groups born at the end of the $1940 \mathrm{~s}$ and the beginning of the $1950 \mathrm{~s}$, who began to reach working age in the 1960 s. As society was not sufficiently prepared for employing these age groups and when, in addition, the latter half of the 1960 s underwent a strong recession this resulted in relatively large unemployment among young people. The 1960 s turned out, in fact, to be a substantial period of emigration. Internal migration was also vigorous. Young people moved away from agriculture-based slowly developing areas to the cities, especially to southern Finland, which was rapidly undergoing industrialization and urbanization.

In the following we will examine more closely the regional effects of internal migration and emigration on the size of the large age groups. We will also determine to what extent new jobs should have been created in different parts of the country so that a loss by migration would have been avoided. We will also present some wiews of the future.

\section{A regional examination of the industrial structure and the labor force supply}

In addition to the rapid growth in the number of the working-age population the 1960 s also saw a record-breaking transition process in the industrial structure compared to other countries. The decrease in jobs in agriculture can be estimated at 300000 , when it is assumed that the number of jobs equals the number of economically active persons. The increase in the labor force supply caused by the increase in the working-age population would have been 280000 
without emigration (the proportion of economically active persons is assumed to be $68 \%$, which is the same as in the working-age population on the average). A total of 570000 jobs would thus have been needed, if it would have been possible to arrange employment for everyone living in Finland in the 1960 s and reaching working age in the 1960 s.

In the service industries the number of jobs grew by 250000 and in the processing industries jobs grew by 121000 making a total of 371000 . The increase should have been 200000 higher, so that it would have corresponded to the potential need. Table 1 shows the potential increase in the labor force supply in the different provinces and compares the increase to the development of the number of jobs.

$\mathrm{Table}$ 1. Changes in the working-age population, the labor force and the number of jobs in the 1960 s, examined by province.

\begin{tabular}{|c|c|c|c|c|c|c|c|}
\hline $\begin{array}{l}\text { Region } \\
\text { (province) }\end{array}$ & 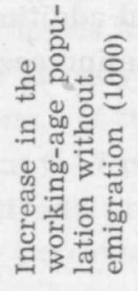 & 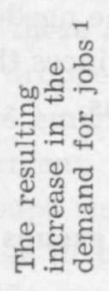 & 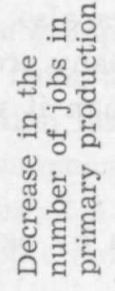 & 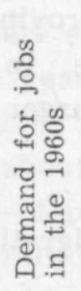 & 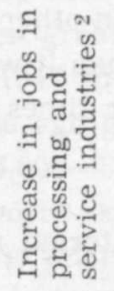 & 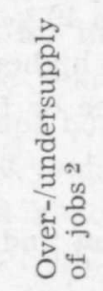 & 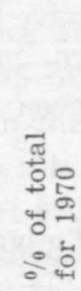 \\
\hline Finland, total & 415 & 280 & 290 & 570 & 371 & -199 & 9 \\
\hline Uusimaa & 41 & 30 & 17 & 47 & 116 & +69 & 14 \\
\hline Turku-Pori & 47 & 33 & 41 & 74 & 52 & -22 & 7 \\
\hline Ahvenanmaa & 1 & 1 & 2 & 3 & 2 & -1 & 3 \\
\hline Häme & 47 & 32 & 29 & 61 & 56 & -5 & 2 \\
\hline Kymi & 26 & 18 & 18 & 36 & 25 & -11 & 7 \\
\hline Mikkeli & 23 & 16 & 22 & 38 & 10 & -28 & 28 \\
\hline Northern Karelia & 28 & 18 & 24 & 42 & 10 & -32 & 40 \\
\hline Kuopio & 32 & 21 & 25 & 46 & 16 & -30 & 27 \\
\hline Central Finland & 28 & 18 & 21 & 39 & 17 & -22 & 23 \\
\hline Vaasa & 46 & 31 & 37 & 68 & 26 & -42 & 22 \\
\hline Oulu & 63 & 41 & 37 & 78 & 29 & -49 & 29 \\
\hline Lapland & 33 & 21 & 17 & 38 & 12 & -26 & 32 \\
\hline
\end{tabular}

1 Calculated by province on the basis of percentages showing persons economically active.

2 Assuming that one job corresponds to each person economically active.

The birthrate has traditionally been higher than average in the eastern and northern parts of Finland, so that the increase in the working-age population has also been highest in these areas. In addition, the predominance of agriculture in the industrial structure resulted in the fact that the undersupply of jobs in the service and processing industries was the largest compared to demand. 
There was such a drop in jobs in agriculture that in the 1960 s the total number of jobs in eastern and northern Finland decreased. Table 1 shows calculations of how many jobs would have been needed in order that the population in the early 1960 s could have been employed in their home provinces, in other words so that neither emigration nor internal migration would have been necessary.

The circa 200000 additional jobs needed to eliminate emigration should have been located primarily in the eastern and northern parts of Finland, so that internal migration could also have been kept down. The province of Uusimaa was the only province where the increase in jobs exceeded the demands of the population in the beginning of the $1960 \mathrm{~s}$. The province would have had to survive with 70000 fewer jobs if there had been no internal migration. The province of Häme would have needed 5000 more jobs, and in the provinces of Turku-Pori and Kymi a job increase of $7 \%$ would have guaranteed employment for the population of the early 1960s. The relatively largest increase in additional jobs would have been needed in the province with the worst migration loss, the province of Northern Karelia, where the needed increase would have been $40 \%$. In other provinces, also, the needed addition would have been $20-30 \%$ higher than it was. In many provinces the increase should thus have been three or four times larger than it was.

\section{Emigration and internal migration by age groups}

By examining age groups nationwide we can determine which age groups have had to suffer most from emigration. When this examination is extended into a regional comparison we will be able to see where those who have remained in Finland are now located regionally. Table 2 examines several age groups born in different years by calculating the percentage of the age group which is still alive and residing in Finland. The method used corresponds to the term used in mortality calculations stating sthe number alive per 100000 births». The size of the age group depends on mortality as well as emigration, but the effect of mortality is a relatively constant 3-4 percent of each age group, so that it will be disregarded. The probability of death does not begin to rise until around the age of 50 .

$\mathrm{Table} 2$. The percentage "remaining" of age groups at various age levels.

\begin{tabular}{rrrrrrrrrrrrrrrrr} 
Age & \multicolumn{10}{c}{ Year of birth } \\
& 1935 & 1940 & 1945 & 1946 & 1947 & 1948 & 1949 & 1950 & 1951 & 1952 & 1953 & 1954 & 1955 \\
0 & 100.0 & 100.0 & 100.0 & 100.0 & 100.0 & 100.0 & 100.0 & 100.0 & 100.0 & 100.0 & 100.0 & 100.0 & 100.0 \\
15 & 91.4 & 90.7 & 94.6 & 93.8 & 92.8 & 92.9 & 92.9 & 94.6 & 94.4 & 95.3 & 94.3 & 94.8 & 93.4 \\
20 & 89.2 & 88.0 & 91.4 & 90.5 & 89.6 & 89.8 & 88.5 & 87.9 & 89.9 & 91.7 & 91.8 & 93.0 & 92.0 \\
23 & 87.0 & 86.3 & 87.9 & 85.5 & 83.7 & 84.8 & 86.8 & 88.9 & 90.0 & 91.0 & - & - & - \\
25 & 85.2 & 82.9 & 83.8 & 84.7 & 85.0 & 85.8 & 87.4 & 88.7 & - & - & - & - & - \\
28 & 83.0 & 81.0 & 85.3 & 86.0 & 85.5 & - & - & - & - & - & - & - & -
\end{tabular}


Already before the age of 15 the age groups born in 1935 and 1940 have decreased more than the others, which has probably been caused by greater infant mortality. An additional cause to some extent could be the migration of some members of these age groups to the other Nordic countries as so-called »war children» (i.e. Finnish children sent to the other Nordic countries for safekeeping for the duration of the war in Finland). The age groups born after the war have suffered the largest losses from emigration. The minimum point of the emigration phase of these age groups is situated around the ages $23-25$ and at this time these age groups have lost 15-16 percent of their original number. Mortality makes up 3-4 percent of this loss. As the age groups grow older return migration increases their size slightly, but even at its highest growth has been only $2-3$ percent. After the age of thirty the size of the age group begins to fall again because of increasing mortality.

Although the migration of the age groups born in the 1950 s is still going on, it already appears that their emigration losses will be definitely smaller than those of the largest age groups. When measured in absolute figures the differences in emigration losses in these age groups are even greater, for the size of the age groups has already dropped from the year 1947 to the year 1955 by almost 20000 persons. If the emigration losses in the age groups born in the early 1950 s remain at $6-7$ percent, this means about $5000-6000$ young people, while in the largest age groups losses of $13-14$ percent equal almost 15000 young people. The percentage of people emigrating to another country seems to fluctuate to some degree in accordance to the size of the age group: the larger the age group, the higher the number of people leaving the country.

Figure 1 examines by province those born in 1947, who can be followed up to the age of 28 . Emigration has reduced the age group by almost 15 percent. Some of those who have remained have moved south to the most industrialized and urbanized regions, mainly to the province of Uusimaa, where the number of inhabitants born in 1947 has increased by 76 percent compared to the original number. An increase of $13 \%$ has also been experienced by the province of Häme. In the other provinces the age group has decreased, with the greatest decrease in eastern Finland. In the province of Northern Karelia one half of the 1947 age group has moved away. In the other provinces of eastern and northern Finland the losses have been about one third of the original number. The age group is reduced most rapidly at and around the age of 20 , at that stage in life when young people finish their education and go off to work. Except for southern Finland this has quite often meant moving to another locality, because enough work has not been available in the young person's hometown area.

It is difficult to make an examination of several age groups by province, because extensive changes in the division of the provinces took place in 1960. If we take the age of 15 as a basis, we can examine the age groups by province without having to calculate the number of births according to the new division of provinces. With current information we can examine how much 
Figure 1. Percentage $(\%)$ of the population of a region belonging to the age group born in 1947, examined by province as of December $31,1975$.

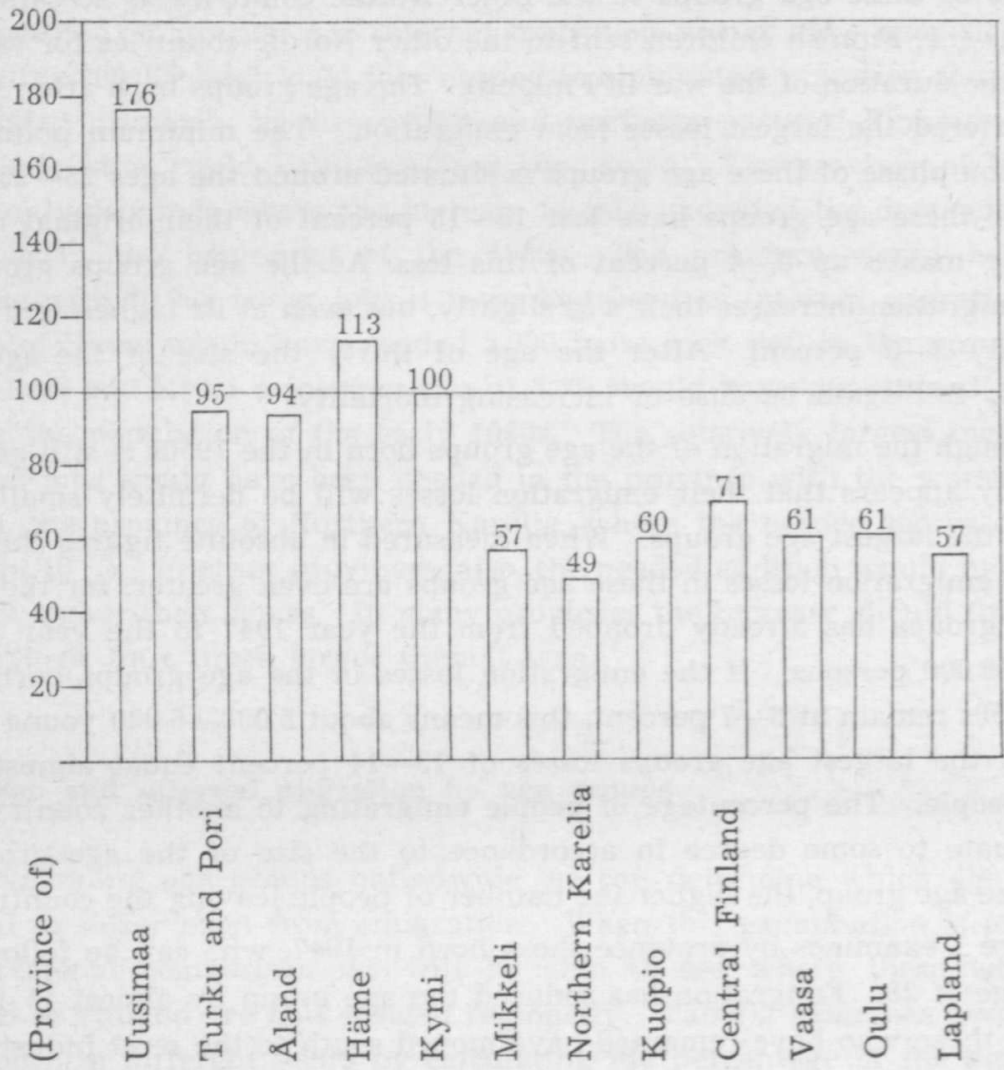

the size of the age groups has decreased from the age of 15 to the age of 25 . In contrast to the previous figure, this examination will disregard migration and deaths which have taken place before the age of 15 . In many provinces the age groups have already been reduced by over 10 percent by this time (Table 3).

While they have grown 10 years older, the age groups in northern and eastern Finland have decreased by roughly one third, in some cases by slightly more. Only in a few provinces in southern Finland have the age groups increased as a result of migration gains. The fact that the age group born in 1950 has grown in four provinces, and that its losses in the other provinces are not as high as they are in the age groups born in 1945 and 1947, is accused by the fact that a smaller percentage of this group has emigrated from Finland. This table shows that the age group born in 1950 has suffered smaller migration losses all around than the older age groups included in this comparison. 
Although the age groups have decreased radically in size in the migrationloss regions, the total population has not decreased in the same proportion, because as a result of a higher than average birthrate the natural increase of the population continued for a rather long period. Not until the 1970 s when migration continually reduced the mother age groups, did the number of births fall below the number of deaths, and as a result the natural increase of the population became a decrease.

$\mathrm{Table} 3$. Changes from the age of 15 to the age of 25 in three age classes by province.

\begin{tabular}{lrrr} 
& \multicolumn{3}{c}{ Age class } \\
Finland, total & 1945 & 1947 & 1950 \\
Uusimaa & 88.6 & 91.6 & 93.7 \\
Turku-Pori & 149.2 & 157.2 & 158.8 \\
Ahvenanmaa & 88.6 & 93.9 & 101.4 \\
Häme & 83.6 & 97.8 & 113.3 \\
Kymi & 98.1 & 104.4 & 106.3 \\
Mikkeli & 84.7 & 87.8 & 88.7 \\
Northern Karelia & 63.3 & 62.8 & 64.1 \\
Kuopio & 55.7 & 56.2 & 58.4 \\
Central Finland & 64.2 & 65.0 & 69.1 \\
Vaasa & 71.5 & 72.9 & 76.6 \\
Oulu & 67.3 & 70.5 & 73.8 \\
Lapland & 67.7 & 67.8 & 71.6 \\
& 66.2 & 66.8 & 66.5
\end{tabular}

\section{Migration in the future}

In the beginning of this century the age groups grew in size almost without exception, but in the 1930 s the birthrate declined. Therefore the number of persons reaching working age in the 1940 s and the 1950 s was low (Table 4). Then also the toll taken by migration losses on the total increase in the working-age population was significant. In the 1960 s the largest change occurred in the number of young people reaching working age with the number rising from 700000 to 920000 . Without emigration the total increase in the workingage population would have risen to 414000 , however 140000 of these persons had to go abroad to earn their living. Because the age structure of the population has grown older, the number of persons reaching retirement age has risen, with an especially rapid increase in the 1960 s. However, no noticeable changes have taken place in the number of deaths occurring during working age.

In the 1970s the size of the age groups reaching working age is still larger than the total of persons retiring and persons who died while of working age, 
$\mathrm{Table} 4$. Changes in the working-age population $1940-1990$.

\begin{tabular}{|c|c|c|c|c|c|c|c|c|}
\hline 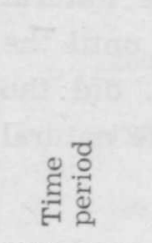 & 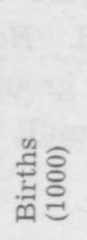 & 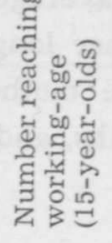 & 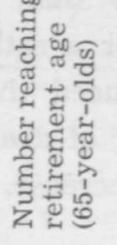 & 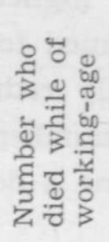 & 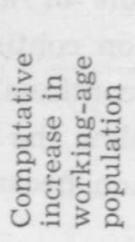 & 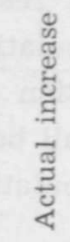 & 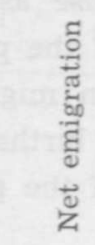 & 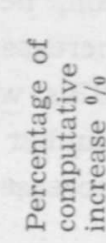 \\
\hline $1926-30$ & 381 & & & & & & & \\
\hline $1931-35$ & 344 & & & & & & & \\
\hline $\begin{array}{l}1936-40 \\
1941-45\end{array}$ & $\begin{array}{l}362 \\
405\end{array}$ & 338 & & & & & & -44 \\
\hline $\begin{array}{l}1941-45 \\
1946-50\end{array}$ & 524 & 313 & 122 & $\begin{array}{r}158 \\
88\end{array}$ & $\begin{array}{r}64 \\
103\end{array}$ & $\begin{array}{l}36 \\
56\end{array}$ & $\begin{array}{l}-28 \\
-47\end{array}$ & $\begin{array}{l}-44 \\
-46\end{array}$ \\
\hline $1951-55$ & 458 & 327 & 128 & 68 & 131 & 97 & -34 & -26 \\
\hline $1956-60$ & 422 & 374 & 138 & 67 & 169 & 127 & -42 & -25 \\
\hline $1961-65$ & 404 & 489 & 170 & 71 & 248 & 193 & -55 & -22 \\
\hline $1966-70$ & 361 & 432 & 194 & 72 & 166 & 81 & -85 & -51 \\
\hline $1971-75$ & 306 & 398 & 224 & 69 & 105 & 125 & +20 & +19 \\
\hline $1976-80^{1}$ & . & 382 & 219 & 73 & 90 & .. & . & . \\
\hline $1981-85$ & $\cdots$ & 342 & 200 & 76 & 66 & . & $\cdots$ & \\
\hline $1986-90$ & .. & 301 & 226 & 80 & -5 & .. & . & \\
\hline
\end{tabular}

resulting in an increase in the working-age population. This increase is, however, only one half of the increase which took place in the $1960 \mathrm{~s}$. Already in the mid-1980s - as a result of the reoccurrance of the migration losses in 1975 , possibly somewhat earlier - the situation may change. At this time the age groups born in the early 1970 s will come of working age, and their number will be less than those leaving the working-age population. The rapid growth phase of the working-age population will become a period of decrease after this.

The yearly amount of internal migration grew with a few exceptions from the $1950 \mathrm{~s}$ all the way to the early 1970s. Although the total number of migrants grew, at the same time the components of migration - outmigration and inmigration - began increasingly to cancel each other out. The net effect of migration decreased, that is the total loss felt by communities with migration loss decreased and, of course, at the same time the total gain experienced in communities with migration gain decreased. The migration gains cities have experienced have also decreased. The decline in the net effect of migration quickened in the beginning of the 1970 s, when the population loss of migration loss communities dropped from 50000 persons in 1970 to 20000 persons in 1976 and the migration gain in the cities decreased from 20000-30000 persons to almost none. Most of the largest cities began to feel population loss.

1 Figures are based on a forecast: Population projection by communes 1975-2010 (Kunnittainen väestöennuste 1975-2010 TK VA 1975: 13). 
One reason for the decline in population loss is the fact that the age groups currently of migration age are definitely smaller than the large age groups who migrated in the $1960 \mathrm{~s}$. The diminished age groups assert less pressure on the schools and job markets of their native districts, so that migration is not needed to the same extent as it was in the 1960 s. Figure 2 examines the age pyramids of 1975 in the urban community of Vantaa, which experienced great population gains from inmigration, and in the rural communities of Northern Karelia, which is a typical migration loss region.

Figure 2. The age pyramids of the rural communities of the province of Northern Karelia and of the urban community of Vantaa.
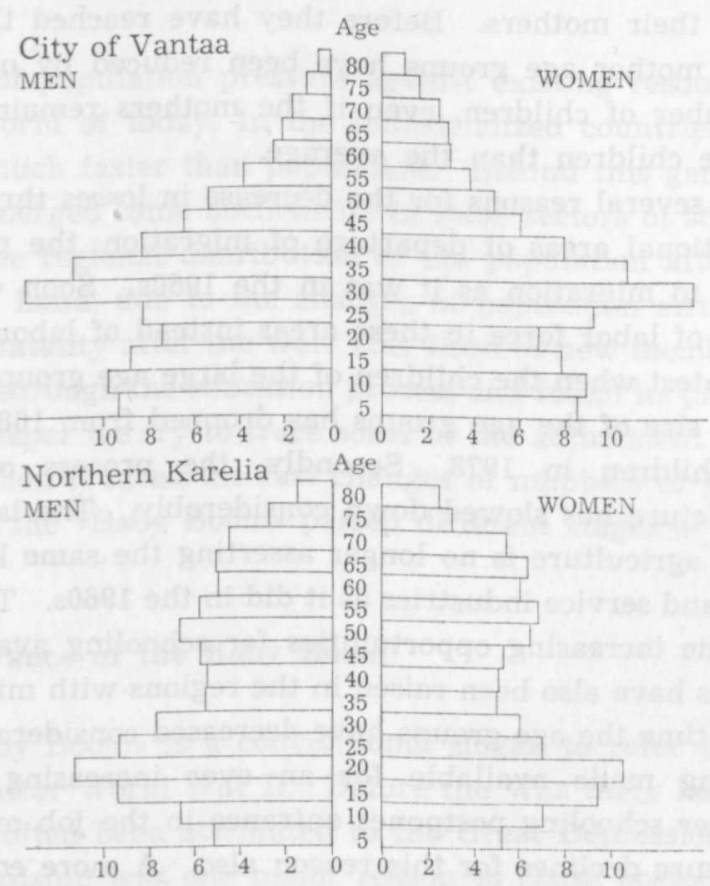

In Vantaa the largest age groups are of migration age, that is $20-29$ years old. These large age groups have also guaranteed abundant child age groups compared to the average, so that later, also, the number reaching working age in Vantaa will remain at the current level or may even rise.

In the rural communities of the province of Northern Karelia the losses by migration have been relatively the largest, which can be seen as a definite narrowing in the age pyramid from the 20-year-olds all the way to the 40 -yearolds. For example, the 25-29-year-old age group was originally almost double 
in size, and even greater among women. In the rural communities of the province the 10-19-year-old age group is currently the largest. If these young people are not guaranteed the opportunity to get an education and make a living in their home province, some of them may be forced to migrate, but the percentage of migrants will hardly rise as high as among the largest age groups. The age groups below 10 years of age are already smaller than the age groups now retiring from the work force, so that they will not even replace those leaving the labor force. If in the future the economy needs a labor force at least equal in size to the current one, these age groups should easily find themselves jobs in their home province. In Northern Karelia the child age groups are small, even though fertility is higher than average. The child age groups have decreased because women have migrated from the province before bearing children or if they did give birth to children before they migrated, these children left with their mothers. Before they have reached their best childbearing years the mother age groups have been reduced by over half, which decreases the number of children, even if the mothers remaining behind did give birth to more children than the average.

Thus there are several reasons for the decrease in losses through migration. First, in the traditional areas of departure of migration, the population is no longer susceptible to migration as it was in the 1960 s. Soon we will be able to speak of a lack of labor force in these areas instead of labor force reserves, beginning at the latest when the children of the large age groups reach the age of migration. The size of the age groups has dropped from 108000 children in 1947 to 57000 children in 1973. Secondly, the process of transition in the industrial structure has slowed down considerably. The labor force being relinquished from agriculture is no longer asserting the same kind of pressure on the processing and service industries as it did in the $1960 \mathrm{~s}$. Thirdly, mention can be made of the increasing opportunities for schooling available to youth. Student admissions have also been raised in the regions with migration loss and when at the same time the age groups have decreased considerably, this results in further training made available for an ever increasing share of each age group. Further schooling postpones entrance in the job market to a later date, so that pressure declines for this reason also. A more equal distribution in itself of student admissions already checks migration, because it has been found that students often find employment in the locality where they have studied. In addition the government has increasingly begun to focus attention on the equalization of differences in regional development, which will probably decrease the pressure to migrate especially in the 1980 s. 